\title{
PRODUÇÃO DE BIOSSURFACTANTE POR Bacillus sp. EM MEIO MÍNIMO CONTENDO GLUCOSE
}

Kátia Andréa Domingos de Morais ${ }^{1}$; Renan de Souza Soares ${ }^{2}$; Marcus Vinícius Forzani Araújo²; Bruno Francesco Rodrigues de Oliveira'; José Daniel Gonçalves Vieira $^{4}$

1 Mestre em Medicina Tropical (Microbiologia), Universidade Federal de Goiás 2 Mestrandos em Ciências Ambientais, Universidade Federal de Goiás

3 Mestre em Biologia da Relação Parasito-Hospedeiro, Universidade Federal de Goiás

4 Professor Doutor do Instituto de Patologia Tropical e Saúde Pública da Universidade Federal de Goiás (jdgvieira62@gmail.com) Goiânia-Brasil

Recebido em: 08/09/2015 - Aprovado em: 14/11/2015 - Publicado em: 01/12/2015 DOI: http://dx.doi.org/10.18677/Enciclopedia_Biosfera_2015_025

\begin{abstract}
RESUMO
A biorremediação utiliza substâncias emulsificadoras, surfactantes, para mitigar contaminações ambientais. Nesse estudo, foi realizado o isolamento de 27 microorganismos a partir de amostras de solo próximas a postos de combustíveis e desses, foi selecionando através de atividade hemolítica um isolado, Bacillus sp. BRUFG 18, como produtor de biossurfactantes. Para a caracterização da produção de bioemulsificantes, amostras de meio mínimo acrescido de glucose ou óleo diesel foram coletadas por sete dias e $\mathrm{opH}$, índice de emulsificação, crescimento microbiano e consumo de glucose foram monitorados. No sétimo dia, o pH variou pouco, entre 7,83 a 8,00, e ocorreu um melhor crescimento de Bacillus sp. BRUFG 18 em meio contendo óleo diesel. Os índices de emulsificação variaram entre 72 e $75 \%$. Os resultados evidenciam a potencialidade de se produzir biossurfactantes comercialmente com uma pequena variação de $\mathrm{pH}$ e utilizando uma fonte de carbono abundante e de baixo custo, como a glucose, a partir de um isolado bacteriano.
\end{abstract}

PALAVRAS-CHAVE: Bacillus, biorremediação, biossurfactantes, glucose, índice de emulsificação, óleo diesel.

\section{PRODUCTION OF BIOSURFACTANTS BY Bacillus sp. IN MINIMAL MEDIUM CONTAINING GLUCOSE}

\begin{abstract}
Bioremediation uses emulsifying substances, surfactants, to mitigate environmental contaminations. On this study, it was carried out the isolation of 27 microorganisms from soil samples near gas stations and from these, it was selected through hemolytic activity one strain, Bacillus sp. BRUFG 18, as a biosurfactant producer. To the characterization of the production of bioemulsifiers, samples containing minimum media supplied with glucose or diesel fuel, were collected in 7 days and $\mathrm{pH}$, emulsification index, microbial growth and glucose consumption were measured. On
\end{abstract}


the seventh day, $\mathrm{pH}$ varied somewhat, between 7,83 to 8,00 , and occurred a better growth of the Bacillus sp. BRUFG 18 in media supplied with diesel fuel. The emulsification index varied between 72 and $75 \%$. Our results show the potentiality to produce biosurfactants commercially with a slight variation of $\mathrm{pH}$ and using a plentiful and with a lower cost carbon source, as glucose, from a bacterial isolate.

KEYWORDS: bioremediation, biosurfactants, Bacillus, diesel fuel, glucose, emulsification index.

\section{INTRODUÇÃO}

A poluição gerada pelo derramamento de petróleo em oceanos, áreas litorâneas e solos promove grandes prejuízos ambientais, sociais e econômicos. Estima-se que apenas na China, entre 1973 a 2011, ocorreram 3.000 acidentes com derramamento de petróleo em ambiente marinho (ASSADI \& TABATABAEE, 2010; EL-SHESHTAWY et al., 2014; DONGDONG et al., 2015). Desta maneira, a biorremediação destaca-se como uma importante ferramenta de redução dessas perdas, devido a sua competência em mitigar processos de poluição ambiental envolvendo compostos fósseis e seus derivados (SOUSA et al., 2014).

Biorremediação caracteriza-se pela utilização ex situ ou in situ de organismos ou metabólitos produzidos por estes com a finalidade de atenuar, diminuir ou extinguir contaminações ambientais (ANDRADE et al., 2010). O processo de remoção de óleos e produtos oleosos do meio ambiente necessita de substâncias que possuem a capacidade de emulsificarem estes materiais além de produzir estabilidade ao emulsificado formado. Estas substâncias são os surfactantes. Entre os surfactantes, aqueles de origem microbiana (biossurfactantes), possuem grande interesse em relação aos surfactantes sintéticos pois possuem baixa toxicidade, alta biodegradação, melhor compatibilidade com o meio ambiente, alta seletividade e especificidade em extremos de $\mathrm{pH}$, temperatura e salinidade, e capacidade de serem sintetizados a partir de compostos renováveis (VAZ et al., 2012; JOSHI et al., 2013a; SACHDEV; CAMEOTRA, 2013; BHARALI et al., 2014)

Biossurfactantes são moléculas anfifílicas produzidas por várias espécies de fungos, leveduras e bactérias, sendo BUSHNELL \& HAAS, em 1941, os primeiros a demonstrarem a produção de biossurfactantes por isolados de Corynebacterium simplex e Pseudomonas sp. em meio mineral suplementado com querosene, óleo mineral ou parafina (BANAT 1995a e b; DAS et al., 1998; GUDINA et al., 2010; HENKEL et al., 2012; SACHDEV \& CAMEOTRA, 2013; SOUSA et al., 2014).

O biocomposto pode estar ligado às estruturas de compartimentalização da célula microbiana ou ser excretado. Do ponto de vista fisiológico os biossurfactantes possuem a função de facilitar o transporte de nutrientes através da membrana plasmática microbiana e auxiliar a interação entre o micro-organismo e o ambiente circundante (ASSADI \& TABATABAEE, 2010; MULLER et al., 2012). De acordo com suas características físico-químicas, os biossurfactantes podem ser divididos em categorias distintas: glicolipídios, lipopeptídeos, lípidos neutros, fosfolípidos, ácidos graxos, dentre outros (ASSADI \& TABATABAEE, 2010; SACHDEV \& CAMEOTRA, 2013). Como exemplo, linhagens de Bacillus spp. possuem capacidade de produzir dois eficientes biossurfactantes pertencentes ao grupo dos lipopeptídios, o surfactin e o lichenysin (JOSHI et al., 2013b).

$\mathrm{Na}$ indústria petrolífera, os biossurfactantes possuem, quando comparados aos surfactantes sintéticos, as vantagens de serem mais seletivos e eficientes perante diferentes tipos de óleos e condições de extração dos reservatórios e possuírem a capacidade de reutilização por meio de regeneração (PEREIRA et al., 
2013a; SACHDEV \& CAMEOTRA, 2013). Além destas vantagens, o composto de natureza biológica pode ser utilizado com uma mínima purificação, ou seja, os microorganismos podem ser utilizados in situ, sem provocar danos ao meio ambiente (GUDINA et al., 2013; JOSHI et al., 2013b).

A produção de biossurfactantes é mais onerosa que seu similar sintético devido a diferentes fatores que influenciam diretamente a manufatura do composto de interesse, como as condições durante a fermentação, as fontes de nitrogênio e carbono presentes no meio de cultura e a cepa microbiana utilizada (JOSHI et al., 2013a; BHARALI et al., 2014). O sucesso da produção comercial de biossurfactantes, portanto, depende da otimização de produção, utilizando substratos de baixo custo tais como coprodutos industriais (glicerol) e fontes lignocelulósicas e da seleção de novas linhagens microbianas melhor produtoras (HENKEL et al., 2012; SOUSA et al., 2012; VAZ et al., 2012; PEREIRA et al., 2013a; PEREIRA et al., 2013b; AL-WAHAIBI et al., 2014). Neste contexto esse trabalho teve como objetivo o isolamento e seleção de nova cepa de Bacillus sp. produtora de biossurfactantes e a avaliação da produção de surfactante em meio de cultura mineral suplementado com óleo diesel e/ou glucose como fontes únicas de carbono.

\section{MATERIAL E MÉTODOS}

\section{Coleta e processamento das amostras}

Seis amostras de solos próximas às bombas de óleo diesel foram coletadas (profundidade de $0-10 \mathrm{~cm}$ ) em três diferentes postos de combustíveis no município de Goiânia, Goiás. As amostras individuais de cada posto de combustível foram reunidas (aproximadamente $30 \mathrm{~g}$ ) constituindo um único "pool" para o isolamento de micro-organismos. As amostras foram processadas no Laboratório de Microbiologia Ambiental e Biotecnologia (LAMAB) do Instituto de Patologia Tropical e Saúde Pública da Universidade Federal de Goiás (IPTSP/UFG).

\section{Isolamento e identificação dos micro-organismos}

Para o isolamento de micro-organismos que utilizam de óleo diesel como fonte única de carbono, foi utilizada a metodologia de enriquecimento seletivo. Uma sub amostra $(5,0 \mathrm{~g})$ foi transferida para um Erlenmeyer com capacidade de $500 \mathrm{~mL}$ contendo $100 \mathrm{~mL}$ de meio mineral. Este meio consistiu de (g/L): $\mathrm{NaCl} 5,0 \mathrm{~g}, \mathrm{~K}_{2} \mathrm{HPO}_{4}$ $1,0 \mathrm{~g}, \mathrm{NH}_{4} \mathrm{H}_{2} \mathrm{PO}_{4} 1,0 \mathrm{~g}$, $\left(\mathrm{NH}_{4}\right) \mathrm{SO}_{4} 1,0 \mathrm{~g}, \mathrm{MgSO}_{4} .7 \mathrm{H}_{2} \mathrm{O} 0,2 \mathrm{~g}$ e $\mathrm{KNO}_{3} 3,0 \mathrm{~g}, \mathrm{pH} 7,0$. (CUNHA \& LEITE, 2000). O meio foi suplementado com 1,0\% (v/v) de Óleo Diesel Petrobrás ${ }^{\circledR}$, não aditivado, como fonte única de carbono. Os frascos foram incubados a $30^{\circ} \mathrm{C}$, sob agitação (shaker) a $180 \mathrm{rpm}$. A cada três dias, alíquotas correspondentes a $1,0 \%$ ( $/ \mathrm{v}$ do meio mineral) foram retiradas e transferidas para meio mineral contendo óleo diesel, recém-preparado, e incubadas sob as mesmas condições anteriormente descritas. Após 12 dias de incubação, $1.0 \mathrm{~mL}$ das alíquotas foram retiradas, diluídas em solução salina esterilizada a $0,85 \%$, até a diluição de $10^{-}$ 7. Alíquotas de $100 \mu \mathrm{L}$ de cada diluição foram inoculadas em placas de Petri contendo ágar nutriente, com o auxílio da alça de Drigalsky e incubadas à $30^{\circ} \mathrm{C}$ por 14 dias até o desenvolvimento de colônias (VECHIOLLI et al., 1990; CUNHA \& LEITE, 2000).

As colônias desenvolvidas foram isoladas e purificadas utilizando a técnica de esgotamento em ágar nutriente. Este procedimento foi repetido até a obtenção de colônias puras, confirmadas por coloração de Gram. Os isolados obtidos foram inoculados em caldo $\mathrm{BHI}$ e incubados por $24-48$ horas a $30^{\circ} \mathrm{C}$. Os micro-organismos 
foram mantidos em glicerol a $40 \%$ em freezer a $-20^{\circ} \mathrm{C}$ para a sua preservação. As amostras também foram caracterizadas com testes bioquímicos com o uso do painel $\mathrm{BBL}^{\mathrm{TM}}$ Crystal $^{\mathrm{TM}}$ Gram-positive (GP) Identification (ID) System (BD ${ }^{\circledR}$ ), composto de 29 reações.

\section{Seleção dos micro-organismos produtores de biossurfactantes em meio de cultura sem hidrocarbonetos}

Para a seleção de micro-organismos produtores de biossurfactantes foi utilizada a metodologia descrita por MULLIGAN et al., (1984). Células bacterianas isoladas foram crescidas em tubos de cultura contendo $5,0 \mathrm{~mL}$ de caldo $\mathrm{BHI}$ a $30^{\circ} \mathrm{C}$ por 48 horas. Após este período, os isolados foram inoculados em placas de Petri contendo ágar sangue de carneiro a 5,0\% com o auxílio de uma multialça, e incubadas novamente a $3^{\circ} \mathrm{C}$ por dois dias. A presenç a de um halo de hemólise ao redor das colônias bacterianas testadas sugere a capacidade microbiana de produção de biossurfactante. A confirmação da síntese de biossurfactante foi realizada pela determinação da produção em meio mineral contendo glucose ou óleo diesel.

\section{Produção de biossurfactantes em meio mineral contendo glucose ou óleo diesel}

Visando a confirmação da produção de biossurfactante e o estudo das condições de produção, duas condições foram comparadas. Na primeira foi utilizado o meio de cultura mineral anteriormente descrito (CUNHA \& LEITE, 2000), acrescido de $1,0 \%(\mathrm{~m} / \mathrm{v})$ de glucose e a outra condição o mesmo meio mineral acrescido de $1,0 \%$ (v/v) de Óleo Diesel Petrobrás ${ }^{\circledR}$ não aditivado. Uma suspensão de células do micro-organismo selecionado quanto à formação de hemólise em ágar sangue de carneiro a $5,0 \%$ foi utilizada como inóculo. A suspensão microbiana foi obtida previamente cultivando-se 0 isolado em $150 \mathrm{~mL}$ de caldo $\mathrm{BHI}$, em frasco tipo Erlenmeyer, com capacidade de $500 \mathrm{~mL}$. Os frascos foram incubados em shaker a $30{ }^{\circ} \mathrm{C}$, por 48 horas a $180 \mathrm{rpm}$. Esta suspensão de cél ulas foi inoculada, na proporção de $15 \%$ (v/v) em frascos tipo Erlenmeyer com capacidade de $500 \mathrm{~mL}$, contendo meio mineral. Os frascos foram divididos em três grupos: no primeiro foi adicionado a glucose como fonte de carbono (concentração final de 1,0\% $\mathrm{m} / \mathrm{v}$ ), no segundo Óleo Diesel Petrobrás ${ }^{\circledR}$ não aditivado como fonte de carbono (concentração final de $1,0 \% \mathrm{v} / \mathrm{v}$ ) e no terceiro, somente água esterilizada (branco). O volume final de cada frasco foi de $150 \mathrm{~mL}$. Os frascos foram incubados sob agitação a $30^{\circ} \mathrm{C}$, durante sete dias a $180 \mathrm{rpm}$. Os experimentos foram realizados com três repetições. Alíquotas de $6,0 \mathrm{~mL}$ de cada grupo foram coletadas em intervalos de 24 horas. As alíquotas foram divididas em dois tubos de vidro previamente limpos e estéreis, sendo que um tubo continha $5,0 \mathrm{~mL}$ e o outro tubo continha $1,0 \mathrm{~mL}$. Os tubos contendo $5,0 \mathrm{~mL}$ foram centrifugados à $10.000 \mathrm{rpm}$ por 10 minutos. O sobrenadante obtido de cada amostra foi utilizado para a determinação dos seguintes parâmetros: índice de emulsificação (E5 e E24), pH e quantificação de glucose. A curva de crescimento microbiano foi determinada com as alíquotas de $1,0 \mathrm{~mL}$.

\section{Índice de Emulsificação (E5 e E24)}

Para a determinação do índice de emulsificação toda a vidraria utilizada foi lavada previamente com Extran ${ }^{\circledR}$ neutro, enxaguado três vezes com água quente e três vezes com água deionizada para a eliminação de quaisquer resíduos que 
pudessem interferir na análise. Das amostras coletadas nos intervalos de 24 horas (5,0 mL), 2,0 mL do sobrenadante foram utilizados para a determinação do Índice de Emulsificação. O ensaio consistiu na mistura destes 2,0 mL com 2,0 mL de Óleo Diesel Petrobrás ${ }^{\circledR}$ não aditivado. A mistura foi homogeneizada por dois minutos em vórtex e após este período, os tubos foram deixados em repouso por cinco minutos (E5). A altura da camada emulsificada $(\mathrm{mm})$ e a altura total da coluna líquida $(\mathrm{mm})$ foram então determinadas e o índice de emulsificação calculado segundo a fórmula:

$$
\mathrm{IE}=\frac{\text { Altura da camada emulsificada }}{\text { Altura total da camada líquida }} \times 100
$$

Para a determinação do E24, as medidas foram repetidas após 24 horas e o índice calculado pela mesma fórmula. O índice E24 representa a estabilidade da emulsificação produzida pelo biossurfactante após 24 horas (SNEHA et al., 2012).

\section{Determinação da curva de crescimento microbiano}

A curva de crescimento do isolado produtor de biossurfactante foi determinada espectrofotometricamente. As alíquotas de 1,0 mL previamente selecionadas foram transferidas para cubetas de quartzo e a absorbância determinada em espectrofotômetro (Pharmacia 2000) com o cumprimento de onda $600 \mathrm{~nm}$. Após a leitura, as amostras pertencentes a cada grupo (diesel, glucose e branco) foram diluídas até $10^{-7}$ utilizando solução salina esterilizada $(0,85 \%)$. Para cada diluição, $10 \mu \mathrm{L}$ foi inoculado (em triplicata), sob a forma de microgotas, em placas de Petri contendo ágar nutriente. Após 24 horas de incubação à $30^{\circ} \mathrm{C}$, as colônias presentes foram contadas e o resultado expresso em UFC/mL (ROMEIRO, 1989). A correlação entre os valores obtidos de turbidez (absorbância) e número de células viáveis permitiu a construção do gráfico de crescimento microbiano.

\section{Quantificação de glucose}

A glucose foi quantificada enzimaticamente pelo método da glucose-oxidase (Kit Gold Analisa-Diagnóstica) segundo protocolo do fabricante.

\section{Identificação do isolado}

Os isolados obtidos foram caracterizados quanto ao aspecto morfológico das colônias e a sua afinidade aos corantes de Gram, sendo para identificação, utilizados testes bioquímicos.

\section{RESULTADOS E DISCUSSÃO}

\section{Isolamento e identificação dos micro-organismos}

Foram obtidas 27 colônias de bactérias com capacidade de se desenvolverem em meio mineral contendo 1,0\% de Óleo Diesel como fonte única de carbono. As bactérias foram caracterizadas pelo aspecto morfológico das colônias e pela afinidade aos corantes de Gram e com testes bioquímicos.

\section{Seleção de micro-organismos produtores de biossurfactantes}

Dos isolados testados, somente o isolado BRUFG 18 apresentou atividade hemolítica, após inoculação em ágar sangue de carneiro a 5,0\% e incubação a $30^{\circ} \mathrm{C}$ por 24 horas. Esse micro-organismo foi caracterizado como bastonete gram-positivo não esporulado, sendo identificado como Bacillus sp. e denominado de Bacillus sp. 
BRUFG 18. AL-BAHRY et al. (2013) efetuaram o isolamento de 72 bactérias formadoras de esporos de amostras de garagens e poços de petróleo na área de AlBahja em Omã, com a seleção de 16 isolados para análise da síntese de biossurfactante em nove diferentes meios de produção. Todos esses isolados foram identificados com base no sequenciamento da porção 16S do DNA ribossômico como pertencentes ao gênero Bacillus, 15 como $B$. licheniformes e 1 como $B$. subtilis.

\section{Determinação do Índice de Emulsificação (E5 e E24)}

$\mathrm{Na}$ Tabela 1 observa-se os resultados de E5 e E24 para o isolado Bacillus sp. BRUFG18 quando cultivado em meio mineral suplementado com $1,0 \%$ de Glucose ou Óleo Diesel Petrobrás ${ }^{\circledR}$ não aditivado, respectivamente. Os IE são semelhantes quanto à porcentagem de emulsificação para o meio de cultivo contendo Glucose e Óleo Diesel Petrobrás ${ }^{\circledR}$ não aditivado. O IE nas duas condições de crescimento atingiu uma fase estacionária de produção com dois dias de crescimento (E24 de 37,5\% e 49,0\% para Glucose e Óleo Diesel Petrobrás ${ }^{\circledR}$ não aditivado, respectivamente) e um pico máximo com sete dias (E24 de 75,15\% e $72,65 \%$ para Glucose e Oleo Diesel Petrobrás ${ }^{\circledR}$ não aditivado, respectivamente). Não foi verificada a presença da camada emulsificada no controle negativo (branco).

TABELA 1 Índice de emulsificação do Bacillus sp. BRUFG 18 em meio mineral, durante sete dias de crescimento à $30^{\circ} \mathrm{C}, 180 \mathrm{rpm}$, com 1,0\% Glucose e com $1,0 \%$ de Óleo Diesel Petrobrás ${ }^{\circledR}$ não aditivado.

\begin{tabular}{cccccc}
\hline \multirow{2}{*}{ Dias } & \multicolumn{2}{c}{ Glucose } & & \multicolumn{2}{c}{ Óleo Diesel } \\
\cline { 2 - 3 } \cline { 5 - 6 } & E5 & E24 & & E5 & E24 \\
\hline 0 & 5.31 & 5.17 & & 7.86 & 7.33 \\
1 & 26.40 & 26.76 & & 28.56 & 28.04 \\
2 & 37.45 & 37.34 & & 49.03 & 49.04 \\
4 & 42.69 & 43.16 & & 39.84 & 39.83 \\
5 & 45.55 & 43.17 & & 36.30 & 38.50 \\
6 & 35.40 & 42.05 & & 52.76 & 52.76 \\
7 & 75.15 & 75.15 & & 72.65 & 72.75 \\
\hline
\end{tabular}

\section{Determinação da curva de crescimento microbiano}

A curva de crescimento do Bacillus sp. BRUFG 18 em meio de cultura mineral suplementado com $1,0 \%$ de glucose ou Óleo Diesel Petrobrás ${ }^{\circledR}$ não aditivado pode ser observado na Figura 1. O isolado foi inoculado com uma concentração inicial de $1,6 \times 10^{5} \mathrm{UFC} / \mathrm{mL}$ para glucose, Óleo Diesel Petrobrás ${ }^{\circledR}$ não aditivado e branco. Observou-se que em ambas as fontes de carbono a fase de crescimento exponencial foi atingida em 48 horas. A população microbiana final após sete dias de crescimento foi de $3,5 \times 10^{7}$ e $3,8 \times 10^{10}$ UFC/mL para glucose e Óleo Diesel Petrobrás ${ }^{\circledR}$ não aditivado, respectivamente. A diferença na população microbiana após os sete dias de crescimento entre os meios acrescidos de glucose e de Óleo Diesel Petrobrás ${ }^{\circledR}$, pode ser explicada pela complexidade química das fontes de carbono. O óleo diesel é uma mistura de hidrocarbonetos saturados e/ou aromáticos longos, podendo ter de nove a 30 átomos de carbono e a glucose é um monossacarídeo de seis átomos de carbono. As diferenças energéticas entre as fontes de carbono, permitiram uma população microbiana final mais abundante. 
Não ocorreu crescimento microbiano no frasco do branco (resultados não mostrados). Os resultados evidenciam um melhor crescimento de Bacillus sp. BRUFG 18 em meio mineral contendo $1,0 \%$ de Óleo Diesel Petrobrás ${ }^{\circledR}$ não aditivado como fonte única de carbono.

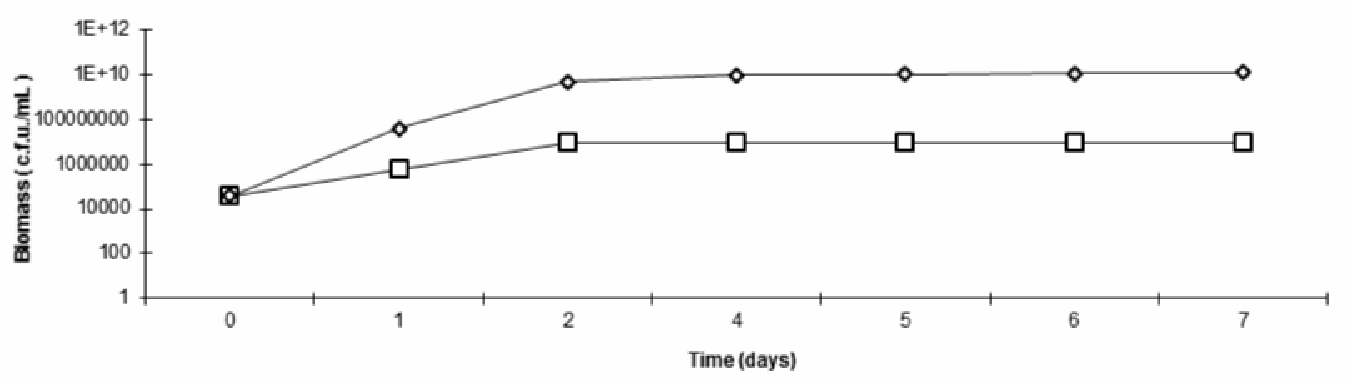

FIGURA 1 Curva de crescimento de Bacillus sp BRUFG 18 Em meio mineral $\mathrm{pH} 7,0$, a $30^{\circ} \mathrm{C}, 180$ rpm. $\diamond$ - Diesel Petrobrás ${ }^{\circledR}$ não aditivado, $(-$ Glucose.

Determinação do pH

$\mathrm{O} \mathrm{pH}$ inicial de ambos meios de cultivo foi de 7,0. Após sete dias, o pH final foi de 7,83 e 8,00 para os meios suplementados com glucose e óleo diesel, respectivamente, não ocorrendo variação de $\mathrm{pH}$ no branco. A pouca variação de $\mathrm{pH}$ durante os sete dias de coleta de amostras, sugere uma capacidade tamponante do meio mínimo. A relativa estabilidade de $\mathrm{pH}$ é essencial para a viabilidade da purificação desse biossurfactante em níveis industriais (FREITAS et al., 2009).

\section{Quantificação de glucose}

Observou-se um consumo de glucose até o sétimo dia de crescimento (Fig. 2). Após este período não foi detectada a presença da mesma no meio de cultivo. No meio de cultivo suplementado com Óleo Diesel Petrobrás ${ }^{\circledR}$ não aditivado não foi detectada a presença deste carboidrato durante o período analisado. GOUVEIA et al., (2003) determinando a produção de biossurfactante por bactérias isoladas de poços de petróleo observaram que a produção não estava associada ao crescimento tendo em vista que a concentração máxima fora obtida durante a fase estacionária de crescimento. Analisando os resultados demonstrados nos gráficos do Índice de Emulsificação (E5 e E24) (Tabela 1) e da curva de crescimento (Figura 2), observase que a produção do biossurfactante em meio contendo glucose e óleo diesel como fonte única de carbono ocorrem na fase exponencial de crescimento, sugerindo uma produção constitutiva. 


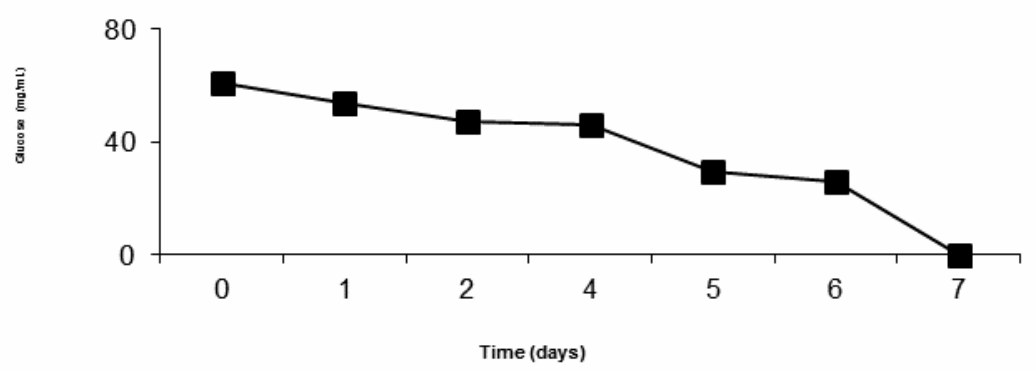

FIGURA 2 Consumo de glucose em meio mínimo suplementado com o monossacarídeo.

\section{CONCLUSÃO}

Os biossurfactantes possuem aplicação limitada, mesmo com inúmeros estudos, como esse, comprovando o elevado potencial e as vantagens ambientais frente aos surfactantes químicos. Estas limitações estão relacionadas principalmente com o alto custo na produção e purificação dessas substâncias (BANAT et al., 2010). A investigação do perfil químico estrutural da biomolécula por técnicas de maior complexidade, como a de cromatografia, é o principal objetivo futuro para complementação desse estudo. A identificação em nível de espécie do Bacillus sp. BRUFG 18 também se faz necessária para estudos posteriores de otimização da síntese de biossurfactantes. Os resultados obtidos corroboram com a literatura em relação à produção de biossurfactantes por Bacillus spp., sendo os microorganismos desse gênero promissores para aplicações ambientais de biossurfactantes, como a biorremediação de hidrocarbonetos pesados. Os resultados também evidenciaram a possibilidade de se produzir biossurfactantes a partir de fontes de carbono abundantes e de baixo custo, como a glucose, podendo assim diminuir os custos de síntese de biossurfactantes e torná-los comercialmente viáveis. A pequena variação do $\mathrm{pH}$ no final dos sete dias de coleta de amostras representa mais um fator para a utilização comercial desse isolado de Bacillus para a produção de biossurfactante viáveis para aplicação.

\section{REFERÊNCIAS}

AL-BAHRY, S. N.; ELSHAFIE, A. E.; AL-WAHAIBI, Y. M.; AL-BEMANI, A. S.; JOSHI, S. J.; AL-LAWATI, A. Isolation and characterization of biosurfactant/biopolymer producing spore forming bacteria from oil contaminated sites and oil field of Oman. APCBEE Procedia, v. 5, p. 242-246, 2013.

AL-WAHAIBI, Y; JOSHI S.; AL-BAHRY, S.; ELSHAFIE, A.; AL-BEMANIA, A.; SHIBULAL, B. Biosurfactant production by Bacillus subtilis B30 and its application inenhancing oil recovery. Colloids and Surfaces B: Biointerfaces, v. 114, p. 324333, 2014.

ANDRADE, J. A.; AUGUSTO, F.; JARDIM, I. C. S. F. Biorremediação de solos contaminados por petróleo e seus derivados. Eclética Química. v. 35, n. 3, p. 17-43, 2010. 
ASSADI, M. M.; TABATABAEE, M. S. Biosurfactants and their use in upgrading petroleum vacuum distillation residue: a review. International Journal of Environmental Research, v. 4, n. 4, p. 549-572, 2010.

BANAT, I. M. Biosurfactants production and possible uses in microbial enhanced oil recovery and oil pollution remediation: a review. Bioresource Technology, v. 51, n. 1, p. 1-12, 1995a.

BANAT, I. M. Characterization of biosurfactants and their use in pollution removal state of the art. Acta Biotechnologica, v. 15, n. 3, p. 251-267, 1995b.

BANAT, I. M.; FRANZETTI, A.; GANDOLFI, I.; BESTETTI, G.; MARTINOTTI, M. G.; FRACCHIA, L.; SMYTH, T. J.; MARCHANT, R. Microbial biosurfactants production, applications and future potential. Applied Microbiology and Biotechnology, v. 87, n. 2, p. 427-444, 2010.

BHARALI, P.; SINGH, S. P.; DUTTA, N.; GOGOI, S.; BORA, L. C.; DEBNATHC, P; KONWARA, B. K. Biodiesel derived waste glycerol as an economic substrate for biosurfactant production using indigenous Pseudomonas aeruginosa. RSC Advances, v. 4, n. 73, p. 38698-38706, 2014.

BUSHNELL, L. D.; HAAS, H. F. The utilization of certain hydrocarbons by microorganisms. Journal of Bacteriology, v. 41, n. 05, p. 653-673, 1941.

CUNHA, C. D.; LEITE, S. G. F. Gasoline bioderadation in different soil microcosms. Brazilian Journal of Microbiology, v. 31, n. 1, p. 45-49, 2000.

DAS, M.; DAS, S. K.; MUKHERJEE, R. K. Surface active properties of culture filtrates of a Micrococcus species grown on n-alkanes and sugars. Bioresource Technology, v. 63, n. 3, p. 231-235, 1998.

DONGDONG, L.; BIN, L.; CHENGUANG, B.; MINGHUI, M.; YAN, X.; CHUNYAN, Y. Marine oil spill risk mapping for accidental pollution and its application in a coastal city. Marine Pollution Bulletin, v. 96, p. 220-225, 2015.

EL-SHESHTAWY, H. S.; KHALIL, W. N. M. K.; ABDALLAH, R, I. Monitoring of oil pollution at Gemsa Bay and bioremediation capacity of bacterial isolates with biosurfactants and nanoparticles. Marine Pollution Bulletin, v. 87, p. 191-200, 2014.

FREITAS, F.; ALVES, V. D.; CARVALHEIRA, M.; COSTA, N.; OLIVEIRA, R.; REIS, M. A. M. Emulsifying behaviour and rheological properties of the extracellular polysaccharide produced by Pseudomonas oleovorans grown on glycerol byproduct. Carbohydrate Polymers, v. 78, n. 3, p. 549-556, 2009.

GOUVEIA, E. R.; LIMA, D. P. A.; DUARTE, M. S.; LIMA, G. M. S.; ARAÚJO, J. M. Produção de biossurfactantes por bactérias isoladas de poços de petróleo. Revista Biotecnologia Ciência e Desenvolvimento, n. 30, p.39-45, 2003 
GUDINA, E. J.; PEREIRA, J. F. B.; COSTA, R.; COUTINHO, J. A. P.; TEIXEIRA, J. A.; RODRIGUES, L. R. Biosurfactant-producing and oil-degrading Bacillus subtilis strains enhance oil recovery in laboratory sand-pack columns. Journal of Hazardous Materials, v. 261, p.106-113, 2013.

GUDINA, E. J.; TEIXEIRA, J. A.; RODRIGUES, L. R. Isolation and functional characterization of a biosurfactant produced by Lactobacillus paracasei. Colloids and Surfaces B: Biointerfaces, v. 76, n. 3, p. 298-304, 2010.

HENKEL, M.; MÜLLER, M. M.; KÜGLER, J. H.; LOVAGLIO, R. B.; CONTIERO, J.; SYLDATK, C.; HAUSMANN, R. Rhamnolipids as biosurfactants from renewable resources: Concepts for next-generation rhamnolipid production. Process Biochemistry, v. 47, n. 8, p. 1207-1219, 2012.

JOSHI, S. J.; GEETHA, S. J.; GADAF, S.; DESAI, A. J. Optimization of bench-scale production of biosurfactant by Bacillus licheniformis R2. APCBEE Procedia, v. 5, p. 232-236, 2013a.

JOSHI, S. J.; SUTHAR, H.; YADAV, A. K.; HINGURAO, K.; NERURKAR, A. Occurrence of biosurfactant producing Bacillus spp. in diverse habitats. International Scholarly Research Notices, v. 2013, p. 1-6, 2013b.

MÜLLER, M. M. M.; KÜGLER, J. H.; HENKEL, M;, GERLITZKI, M.; HÖRMANN, B.; PÖHNLEIN, M.; SYLDATK, C.; HAUSMANN, R. Rhamnolipids - next generation surfactants? Journal of Biotechnology, v. 162, n. 4, p. 366-380, 2012.

MULLIGAN, C. N.; COOPER, D. G.; NEUFELD, R. J. Selection of microbes producing biosurfactants in media without hydrocarbons. Journal of Fermentation Technology, v. 62, n. 4, p. 311-314, 1984.

PEREIRA, A. G.; PACHECO, G. J.; TAVARES, L. F.; NEVES, B. C.; KRONEMBERGER, F. A.; REIS, S. R.; FREIRE, D. M. G. Optimization of biosurfactant production using waste from biodiesel industry in a new membrane assisted bioreactor. Process Biochemistry, v. 48, n. 8, p. 1271-1278, $2013 \mathrm{~b}$.

PEREIRA, J. F. B.; GUDINA, E. J.; COSTA, R.; VITORINO, R.; TEIXEIRA, A. J.; COUTINHO, J. A. P.; RODRIGUES, L. R. Optimization and characterization of biosurfactant production by Bacillus subtilis isolates towards microbial enhanced oil recovery applications. Fuel, v. 111, p. 259-268, 2013a.

ROMEIRO, R. S. Técnica de microgota para contagem de células bacterianas viáveis em uma suspensão. In: ROMEIRO, R. S. (ed.). Métodos em bacteriologia de plantas. Viçosa: Editora UFV, 1989. p. 117-126, 1989.

SACHDEV, D. P.; CAMEOTRA, S. S. Biosurfactants in agriculture. Applied Microbiology and Biotechnology, v. 97, n. 3, 1005-1016, 2013.

SNEHA, K. S.; PADMAPRIYA, B.; RAJESWARI, T. Isolation and screening of biosurfactants produced by Pseudomonas aeruginosa from oil spilled soils. 
Internacional Journal of Pharmaceutical and Biological Archieve, v. 3, n. 2, p. 321-325, 2012.

SOUSA, M.; DANTAS, I. T.; FELIX, A. K. N.; SANT'ANA, H. B.; MELO, V. M. M.; GONÇALVES, L. R. B. Crude glycerol from biodiesel industry as substrate for biosurfactant production by Bacillus subtilis ATCC 6633. Brazilian Archives of Biology and Technology, v. 57, n. 2, p. 295-301, 2014.

SOUSA, M.; MELO, V. M. M.; RODRIGUES, S.; SANT'ANA, H. B.; GONÇALVES, L. R. B. Screening of biosurfactant-producing Bacillus strains using glycerol from the biodiesel synthesis as main carbon source. Bioprocess and Biosystems Engineering, v. 35, n. 6, p.897-906, 2012.

VAZ, D. A.; GUDINA, J. D.; ALAMEDA, E. J.; TEIXEIRA, J. A.; RODRIGUES, L. R. Performance of a biosurfactant produced by a Bacillus subtilis strain isolated from crude oil samples as compared to commercial chemical surfactants. Colloids and Surfaces B: Biointerfaces, v. 89, p. 167-174, 2012.

VECHIOLLI, G. I.; DEL PANNO, M. T.; PAINCEIRA, M. T. Use of selected autochthonous soil bacteria to enhance degradation of hydrocarbons in soil. Environmental Pollution, v. 67, n. 3, p. 249-258, 1990. 